\title{
QUANTIFICAÇÃO DAS EMISSÕES DE GASES EFEITO ESTUFA - GEEs - SEGUNDO MATRIZ ENERGÉTICA DIESEL OU GNV NO TRANSPORTE PÚBLICO POR ÔNIBUS EM NATAL-RN.
}

\author{
Ricardo Teixeira Gregório de Andrade \\ Tecnólogo em Gestão Ambiental - IFRN. Mestrando em Engenharia de Produção - UFRN, \\ Linha de Gestão Ambiental, rtnatal@gmail.com \\ Prof. Dr. Enilson Medeiros dos Santos \\ Docente da UFRN, enilson@interjato.com.br
}

\begin{abstract}
RESUMO
Dentre os contribuintes à poluição atmosférica mundial, o setor de transportes é responsável por considerável montante de emissões de gases poluentes. As emissões de gases poluentes causam uma gama de prejuízos sanitários, ambientais e, portanto, econômicos. Face à temática do aquecimento global e ao contexto do ganho de créditos de carbono via projetos tipo Mecanismo de Desenvolvimento Limpo (MDL), mostram-se favoráveis os estudos que possibilitem mitigar tais emissões e conseqüentes prejuízos. $\mathrm{O}$ presente estudo destina-se, primordialmente, a demonstrar a quantificação das emissões dos Gases Efeito Estufa - GEE's expedidas pelo transporte público por ônibus da cidade de Natal-RN, no período de 2006 a 2008, tanto para a matriz energética atual, o Diesel, como para o GNV, no caso de hipotética substituição. Por conseguinte, visa a analisar a troca da matriz energética quanto à redução das externalidades e passivo ambiental gerado como conseqüência da atividade de transporte urbano, sendo o foco a temática ambiental. Os cálculos foram realizados tomando por base a metodologia explicitada pelo Painel Intergovernamental de Mudanças Climáticas - IPCC (The International Pannel for Climate Changes), na unidade de $\mathrm{CO}_{2}$ eq. Os cálculos realizados indicam uma redução potencial das emissões em $\mathrm{CO}_{2}$ eq de aproximadamente $49 \%$, evidenciando que este fator deve ser considerado na avaliação mais global da viabilidade desta substituição.
\end{abstract}

PALAVRAS-CHAVE: Gases Efeito Estufa; Mitigação de Emissões; Transporte Público por Ônibus, Diesel, GNV.

\section{GHG'S EMISSIONS VALUATION FOR DIESEL AND NATURAL GAS AS ENERGETIC MATRIX ON PUBLIC TRANSPORT BY BUSES IN NATAL-RN, BRAZIL}

\section{RESUMO}

Among the contributors to global atmospheric pollution, the transports sector is responsible for a considerable amount of pollutant gases emission, which cause a range of prejudices on different segments, as sanitary, environmental and economic. Due to global warming thematic and to the context of carbon credits acquisition, by CDM projects, researches that propose the mitigation of those emissions are promising. The main goal of this study is to demonstrate the Global House Gases - GHG's emissions quantification for the public transport by buses sector of Natal-RN, Brazil, from 2006 to 2008, both to Diesel, the actual energetic matrix, as to Natural Gas, in case of hypothetical substitution. The amount of GHG's were estimated according to the methodology proposed by the IPCC (The 
International Pannel for Climate Changes), on CO2eq unit. The results point a 49\% GHG's emissions reduction, which favorably evidences the substitution from Diesel to Natural Gas on public transport's buses as a considerable proposal to mitigate the emissions and its impacts.

KEY-WORDS: Green House Gases; Emissions Mitigation; Public Transport by Buses; Diesel; Natural Gas. 


\section{QUANTIFICAÇÃO DAS EMISSÕES DE GASES EFEITO ESTUFA - GEEs - SEGUNDO MATRIZ ENERGÉTICA DIESEL OU GNV NO TRANSPORTE PÚBLICO POR ÔNIBUS EM NATAL-RN.}

\section{INTRODUÇÃO}

Dentre os contribuintes à poluição atmosférica mundial, o setor de transportes é responsável por considerável montante de emissões de gases poluentes. As emissões de gases poluentes causam uma gama de prejuízos sanitários, ambientais e, portanto, econômicos. Localmente, ocasionam danos à saúde pública e, por conseguinte, degradação da qualidade de vida nas cidades. Globalmente, ajudam a agravar a concentração dos Gases Efeito Estufa - GEE’s, intensificando o aquecimento global. Logo, pautando-se na ética sanitária e ambiental, deve-se buscar compensar e, ou pelo menos, mitigar tal passivo sócio-ambiental - geração e emissão de tais gases como parcela do output de processos produtivos.

Objetiva-se, principalmente, estimar as emissões de GEE's oriundas do transporte público da cidade de Natal na situação atual, tendo o Diesel como matriz energética, e na situação hipotética da adoção do combustível GNV, no período de 2006 a 2008. Destarte, o estudo visa apresentar uma alternativa para redução da geração de gases poluentes, através da adoção de uma matriz energética mais interessante do ponto de vista ambiental. Subsidiariamente, tenciona-se também demonstrar a metodologia de cálculo empregada na obtenção do quantitativo das emissões de GEE’s.

A pertinência da temática 'transportes públicos' e sua relação direta com o aquecimento global torna esse estudo relevante para:

a) a estruturação paulatina de um diagnóstico mais abrangente do passivo ambiental gerado pelas emissões de GEEs oriundas do transporte público urbano no Brasil; e

b) a propagação da metodologia desenvolvida neste estudo, a qual está atualizada conforme o cenário ambiental mundial atual

\section{FUNDAMENTAÇÃO TEÓRICA}

Hodiernamente, diversas alterações na Natureza têm sido sentidas ao longo de todo o globo. Empiricamente, podemos enumerar diversos exemplos de alterações naturais de causas climáticas - as enchentes e secas estão cada vez mais severas em território nacional, os regimes de chuvas não seguem mais um padrão anual, os Ipês no Nordeste em 2008 só iniciaram sua floração em meados de Outubro. Em relação aos problemas decorrentes das mudanças climáticas no Brasil, o presidente do IPCC, o indiano Rajendra Pashauri, ao ser interrogado, disse que "já estamos tendo, e teremos secas, inundações mais fortes e dificuldades progressivas de abastecimento de água, principalmente nas grandes cidades. Isto vai se agravar mais” (FAJARDO, 2006, p. 12).

Contudo, tais alterações já vêm sendo detectadas, de forma menos perceptível, há algumas décadas, e fomentando, em crescimento exponencial, uma preocupação em diversas áreas do conhecimento, demandando estratégias sócio-político-ecônomicas, bem como desenvolvimentos científicos e tecnológicos para solucionar tais questões.

De fato, a confirmação científica da realidade das mudanças climáticas veio no mais recente relatório do IPCC, em que os mais de 2.500 cientistas de mais de 130 países 
participantes concluíram, após seis anos de estudos e análises, que a elevação da temperatura média global está correlacionada diretamente ao drástico aumento do uso de combustíveis fósseis. As análises sistemáticas do IPCC demonstram que este aumento da temperatura está crescendo e é causado pelas emissões antrópicas acumuladas dos Gases Efeito Estufa (GEE), principalmente o dióxido de carbono $\left(\mathrm{CO}_{2}\right)$, oriundo da queima de combustíveis fósseis, o metano $\left(\mathrm{CH}_{4}\right)$ e o óxido nitroso $\left(\mathrm{N}_{2} \mathrm{O}\right)$.

Em seu Quarto Relatório de Avaliação (IPCC, 2007), o IPCC expõe que “Desde o início da revolução industrial, em 1750, a concentração atmosférica global de dióxido de carbono aumentou de cerca de 280 ppm para 379 ppm, em 2005”. Além disso, de forma a enfatizar a responsabilidade antrópica pelas mudanças climáticas, o relatório apresenta dados de que as emissões fósseis anuais de $\mathrm{CO}_{2}$ aumentaram, aproximadamente, de uma média de 6,4 GtC (1GtC corresponde a 3,67 GtCO2) por ano, na década de 90, para 7,2 GtC por ano, no período de 2000 a 2005 (IPCC, 2007, p.5). Segundo Andrew Weaver, um dos autores do estudo, "É o mesmo que o IPCC vem dizendo há 20 anos, mas com uma certeza científica muito maior” (GUIMARÃES e FAJARDO, 2007, p.20).

Todavia, não há ainda um consenso científico quanto à questão do aquecimento global. Hacbart (2008; 2009) que a variação ascendente da temperatura não é equânime em todo o globo e expõe dados da Universidade do Alabama que indicam que a temperatura global em amio de 2009 ficou $0,18^{\circ} \mathrm{C}$ abaixo da média dos últimos 30 anos, sendo o mês mais frio na Terra desde janeiro de 2000 e o maio com menor temperatura desde 1992. O autor chega a afirmar que o aquecimento global inexistiu na década atual. Entretanto, a despeito das incertezas e discordâncias quanto aos resultados que advirão, as aferições científicas convergem para as maiores variações de temperatura e concentrações atmosféricas já confirmadas. Tal cenário não sugere hesitação, mas sim demanda uma atitude relacionada às causas dessas variações percebidas.

De acordo com o Centro de Gestão e Estudos Estratégicos - CGEE (2008, p.42), as três atitudes possíveis frente a essas preocupações são a inação, adaptação ou mitigação, sendo as mais plausíveis aquelas referentes às duas derradeiras. Quanto à adaptação, as alternativas para controlar as emissões de GEEs seriam utilizar a energia de maneira mais eficiente, reduzindo as emissões futuras, e substituir os recursos energéticos derivados de combustíveis fósseis por outros de fontes renováveis, com menores emissões de carbono por kWh consumido. Já a mitigação visa uma abordagem do manejo do carbono, buscando capturar e armazenar o carbono emitido na atmosfera - 'sequestro de carbono'. As alternativas seriam a reintegração deste à biosfera, pelo aumento da área vegetada, ou a captura por ações físicas e químicas de $\mathrm{CO}_{2}$ nos pontos de produção ou transformação de energia, com sua subseqüente armazenagem em poços de petróleo ou gás exauridos ou nas profundezas dos oceanos (MARTINS, 2005, p.19).

A primeira atitude concreta por parte da comunidade internacional, a respeito deste amplo complexo científico-econômico-tecnológico-diplomático relacionado à mudança do clima, se deu na Conferência das Nações Unidas sobre Meio Ambiente e Desenvolvimento (Rio-92), em 1992, na qual veio a culminar a entrada em vigor do Protocolo de Quioto e a possibilidade de utilização do Mecanismo de Desenvolvimento Limpo (MDL), que atraem cada vez mais a atenção do mundo dos negócios e do setor empresarial.

Dentre os tratados internacionais a respeito do meio ambiente, o Protocolo de Quioto é o de maior relevância em termos da redução das emissões dos GEEs e importância por sua 
abrangência em convocação de países em todo o mundo (sobretudo os mais desenvolvidos) (SCARPINELLA, 2002, p.29). O Protocolo de Quioto, em sua formulação, intencionava em seus 28 artigos definir propostas mais concretas e eficazes para uma real redução das emissões dos GEEs pelas Partes Signatárias. Scarpinella (2002, p.103) diz que o Protocolo de Quioto foi "o documento redigido de maior importância dentre os tratados acerca das questões relacionadas ao meio ambiente”.

Na prática, o Protocolo de Quioto formalizou o acordo de compromissos diferenciados para os envolvidos (países desenvolvidos), aos quais foram aplicadas obrigações de redução ou limitação de emissões entre 2008 e 2012. As reduções, em conjunto, almejam uma redução de pelo menos 5,2\% em relação aos valores dos GEEs emitidos em 1990 (MARTINS, 2005, p.22; SCARPINELLA, 2002, p.102), ressaltando que estão sendo consideradas somente as emissões antropogênicas.

O MDL, constituído no $12^{\circ}$ artigo do Protocolo de Quioto, permite que os países industrializados, a fim de cumprir suas metas de redução, possam comprar reduções certificadas de emissões geradas nos países em desenvolvimento, através de projetos de seqüestro de carbono (CQNUMC, 2008). Esse mecanismo é caracterizado por ser o único dentre os três aplicável a países em desenvolvimento, oferecendo a possibilidade de captação de recursos e, dessa forma, sendo uma oportunidade ímpar para promover o desenvolvimento sustentável e contribuir para os objetivos da Convenção do Clima (CGEE, 2008, p.19). O MDL foi desenvolvido a partir de uma proposta brasileira, a qual intentava à criação de um fundo de desenvolvimento limpo. De acordo com o princípio poluidor-pagador, nesse fundo deveriam ser depositadas verbas pelos países que não conseguissem atingir suas metas de redução. A proposta não foi integralmente acatada, sendo transformada em mecanismo (SCARPINELLA, 2002, p.114; MARTINS, 2005, p.23).

Desta feita, os GEE's passaram a possuir valor econômico, sendo utilizados como moeda ambiental na aquisição das "permissões de poluir" no mercado internacional de emissões de carbono. Implica dizer que a poluição emitida a menos por um país, pode ser comercializada no mercado internacional. Este "saldo" somente poderá ser comercializado se for o resultado do uso de tecnologia mais limpa para realizar o abatimento do carbono (OLIVEIRA JUNIOR, 2005). A unidade de valoração dos GEEs é o $\mathrm{CO}_{2}$ equivalente $\left(\mathrm{CO}_{2} \mathrm{eq}\right)$, o qual representa uma equivalência matemática que permite expressar as emissões de qualquer outro GEE em termos de toneladas de dióxido de carbono.

Assim, a substituição do Diesel pelo GNV como energético motriz no transporte público poderia servir para alavancar recursos para investimento em tecnologias mais limpas, mediante formulação de um projeto de MDL. Contudo, convém salientar que este estudo não se configura um projeto de MDL, podendo ser caracterizado apenas como base sugestiva para tal.

Acrescidas à motivação exposta acima, Oliveira Filho (2006) coloca que a substituição de diesel por gás natural possui também motivações de ordem energética, em termos econômicos e de segurança energética. A mesma é pautada na busca por equilibrar a matriz energética nacional, ao reduzir a importação de petróleo (e dependência dos países exportadores) e intensificar o uso do gás natural. Oliveira Filho (2006) expõe que tal motivação é: 
oportuna nos países onde esta fonte de energia é abundante, tanto por oferta em função de produção doméstica como por importação em condições econômicas e estratégicas vantajosas em comparação com as condições de oferta de petróleo. O Brasil se enquadra nesse perfil, tanto porque ainda importa petróleo para suprir parte da demanda de diesel, como também em função da situação favorável de oferta doméstica de gás natural e de perspectivas favoráveis a longo prazo.

Na prática, o uso exacerbado do óleo diesel como combustível pelo setor de transportes tem colaborado com o majoramento da poluição atmosférica nas grandes cidades e intensificação da dependência do petróleo, indesejável nos países importadores. Ensejando o minoramento destes problemas, nas duas derradeiras décadas, a substituição de diesel no transporte público tem sido adotada em diversas partes do mundo com resultados satisfatórios.

No Brasil, contudo, todas as experiências conduzidas fracassaram e foram gradativamente descontinuadas, restando poucos veículos em operação. No país, tais experiências tiveram início na década de 80, por motivo da adoção, pelo Ministério de Minas e Energia - MME, do Plano nacional de Gás Natural - PLANGÁS, como estratégia governamental em resposta aos dois choques do preço do petróleo na década de 70 seguidos das altas taxas de juros internacionais (NOGUEIRA, 2006).

Natal foi a primeira cidade brasileira a possuir ônibus urbanos movidos a GNV, em programa promovido pela Prefeitura e pela Petrobras, que envolveu o teste de ônibus dedicados a gás Mercedes Benz do Brasil e ônibus diesel-gás convertidos. O programa iniciou em 1983 e chegou a ter em 1991 a maior frota de ônibus a gás do país, com 47 veículos, o correspondente a 15\% da frota urbana da cidade na época (OLIVEIRA FILHO, 2006).

Oliveira Filho (2006) e Nogueira (2006), após compilação e análise de estudos de diversos autores, concluem que os programas de substituição de Diesel por GNV no transporte urbano em Natal e demais cidades brasileiras (São Paulo, Rio de Janeiro, Recife, Salvador, Vitória e Aracaju) obtiveram desempenho insatisfatório devido, principalmente a: a imaturidade tecnológica, a baixa qualidade do gás natural, a fraca logística de acesso ao gás e os custos envolvidos em todo o processo de uso do ônibus a gás. Segundo os autores, os programas, repletos de equívocos político-administrativos, ocorreram de forma esparsa e descoordenada, utilizando os sistemas de transporte das cidades como laboratório de teste para uma tecnologia ainda prematura na época.

Entretanto, nas experiências internacionais, os autores demonstram que os problemas enfrentados foram semelhantes, mas que os mesmos foram solvidos através de incentivos fiscais e financeiros, gestão e logística eficientes e publicidade do mesmo. Como comprovação do sucesso desses países, os autores delineiam a frota movida a gás em 15 países (sendo 12 desenvolvidos), os quais apresentam em média 10\% da frota movida a GNV atualmente, em contraste a apenas 0,04\% para o Brasil. Assim, as experiências destes países podem servir de exemplo a futuros programas brasileiros, fornecendo a metodologia necessária para solver dificuldades e sanar equívocos.

Segundo análise de Oliveira Filho (2006), das causas referentes ao insucesso dos programas nacionais, somente o acesso ao gás nas cidades ainda não está resolvido. Ribeiro (2002), segundo pesquisa feita com mais de 100 agentes integrantes da indústria do Gás Natural, elenca como principais barreiras existentes à lata utilização do GNV no 
Brasil: a ausência de um planejamento do governo que garanta o suprimento do combustível; a inexistência de uma política de manutenção de preços em longo prazo, que encoraje o uso de combustíveis alternativos; e ineficiência de questões normativas, regulatórias e de fiscalização quanto às condições de segurança nos postos de abastecimento e veículos convertidos.

Felizmente, se faz perceptível que as dificuldades citadas podem ser vencidas a partir de um esforço governamental na execução de estudos, planejamentos e políticas que viabilizem, técnica, logística e economicamente, programas de substituição do Diesel por GNV em frotas de transporte público urbanas no país. A volta à cena, nesse momento, de novas intenções para reativação das frotas de ônibus a gás natural no Brasil serve de incentivo a ampliação de estudos para confirmação das dificuldades aparentemente superadas e equacionamento dos obstáculos ainda persistentes.

\section{MATERIAIS E MÉTODOS}

O estudo foi conduzido através das seguintes etapas: compilação dos dados necessários, aplicação da metodologia para os cálculos das emissões de $\mathrm{CO}_{2}$ eq e análise do resultados numéricos obtidos.

Os cálculos do montante das emissões foram pautados na metodologia adotada pelo Painel Intergovernamental de Mudanças Climáticas (The Intergovernamental Panel on Climate Change - IPCC) em suas Diretrizes para Inventários Nacionais de Gases Efeito Estufa (IPCC, 2006). O IPCC é um órgão independente criado em 1988, sendo credenciado e reconhecido pelas Nações Unidas para a normatização do monitoramento dos GEE's e aprovação das decisões da Convenção Quadro sobre Mudança no Clima e do Protocolo de Quioto.

A metodologia do IPCC (2006), explicitada também em Oliveira Júnior (2005) - sendo feitos os necessários ajustes, consiste na multiplicação da energia produzida (trabalho realizado pelo consumo do combustível) pelo índice emissão dos GEEs fornecidos pelo IPCC. Estes índices são apresentados na unidade Kg/TJ, razão pela qual se deve calcular a energia produzida na unidade TJ (equivalendo $10^{6} \mathrm{MJ}$ ).

A fim de se obter a energia produzida, faz-se necessário conhecer inicialmente o consumo de combustível efetivado. Os dados de quilometragem da frota de Natal foram obtidos junto à Secretaria Municipal de Trânsito e Transporte Urbano - STTU, havendo disponibilidade dos mesmos apenas para os exercícios de 2006 a 2008. A Tabela 1 apresenta os dados de quilometragem anual percorrida pela frota de ônibus da cidade de Natal nos exercícios de 2006 a 2008, os consumos de combustíveis e respectivas energias produzidas tanto para o Diesel quanto para o GNV, no caso da substituição hipotética da matriz energética.

O consumo de Diesel foi obtido a partir do rendimento utilizado na planilha do cálculo tarifário do transporte público de Fortaleza (PMF, 2002), na qual os ônibus são caracterizados como veículos pesados e possuem o consumo médio de $2 \mathrm{Km} / \mathrm{l}$, sendo justamente esta a caracterização da frota trabalhada neste estudo. Na tabela, e ao longo do estudo, o consumo hipotético de GNV é estimado em função da adoção do fator de equivalência do GNV em relação ao Diesel, de 0,8l/m³ (RIBEIRO, 2001). 
Tabela 1 - Quilometragem, Consumo e Energia Produzida pelo Transporte Público feito por Ônibus em Natal para os combustíveis Diesel e GNV.

\begin{tabular}{cccccc}
\hline ANO & $\begin{array}{c}\text { Quilometragem } \\
\left(\mathbf{1 0}^{\mathbf{6}} \mathbf{K m}\right)\end{array}$ & $\begin{array}{c}\text { Consumo } \\
\text { Diesel }\left(\mathbf{1 0}^{\mathbf{6}} \mathbf{l}\right)\end{array}$ & $\begin{array}{c}\text { Energia Produzida } \\
\mathbf{( M J )}\end{array}$ & $\begin{array}{c}\text { Consumo } \\
\mathbf{G N V}\left(\mathbf{1 0}^{\mathbf{6}} \mathbf{m}^{\mathbf{3}} \mathbf{)}\right.\end{array}$ & $\begin{array}{c}\text { Energia Produzida } \\
\mathbf{( M J )}\end{array}$ \\
\hline 2006 & 52,50 & 26,25 & $997.301 .757,38$ & 32,81 & $1.157 .214 .048,03$ \\
\hline 2007 & 51,39 & 25,70 & $976.215 .948,79$ & 32,12 & $1.132 .877 .635,56$ \\
\hline 2008 & 54,05 & 27,03 & $1.026 .745 .904,50$ & 33,78 & $1.191 .426 .106,14$ \\
\hline 2006 a 2008 & 157,94 & 78,97 & $3.000 .263 .610,66$ & 98,71 & $3.481 .517 .789,73$ \\
\hline Média anual & $\mathbf{5 2 , 6 5}$ & $\mathbf{2 6 , 3 2}$ & $\mathbf{1 . 0 0 0 . 0 8 7 . 8 7 0 , 2 2}$ & $\mathbf{3 2 , 9 0}$ & $\mathbf{1 . 1 6 0 . 5 0 5 . 9 2 9 , 9 1}$ \\
\hline
\end{tabular}

A energia produzida para o Diesel foi obtida a partir do consumo dividido por mil (para conversão de litros em $\mathrm{m}^{3}$ ) e multiplicado por seus Poder calorífico inferior e percentual de carbono não oxidado. Para o GNV, o procedimento de cálculo é símile, somente adicionando-se à multiplicação o seu Poder calorífico superior. Os respectivos valores para as especificações citadas, bem como índices de carbono não oxidado (monóxido de carbono - CO) constam nas tabelas 2 e 3.

Tabela 2 - Especificações e Índice de Emissão do Diesel.

\begin{tabular}{|c|c|c|}
\hline \multirow[b]{2}{*}{ Especificações do Energético } & \multicolumn{2}{|c|}{ DIESEL } \\
\hline & Valor & Unidade \\
\hline 1) Densidade Específica: & 852 & $\left(\mathrm{Kg} / \mathrm{m}^{3}\right)$ \\
\hline 2) Capacidade Calorífica: & 10.750 & (Kcal/Kg) \\
\hline 3) Equivalência Kcal - J: & 4.190 & (Kcal p/ Joule) \\
\hline $\begin{array}{l}\text { 4) Poder Calorífico Inferior: } \\
{\left[4=(3 \times 2 \times 1) / 10^{6}\right]}\end{array}$ & $38.376,21$ & $\mathrm{MJ} / \mathrm{m}^{3}$ \\
\hline 5) Carbono Não Oxidado: & $0,99^{(1)}$ & $(\%)$ \\
\hline 6) Equivalência GNV - Diesel & 0,80 & Diesel(L) / GNV $\left(\mathrm{m}^{3}\right)$ \\
\hline
\end{tabular}

Tabela 3 - Especificações e Índice de Emissão do GNV.

\begin{tabular}{lcl}
\hline & \multicolumn{2}{c}{ GNV } \\
\cline { 2 - 3 } Especificações do Energético & Valor & Unidade \\
\hline 1) Capacidade Calorífica: & $9.400^{(1)}$ & $\left(\mathrm{Kcal} / \mathrm{m}^{3}\right)$ \\
\hline 2) Equivalência Kcal - J: & 4.190 & $(\mathrm{Kcal} \mathrm{p} / \mathrm{Joule})$ \\
\hline 3) Poder Calorífico Superior: & $39.506,10$ & $\mathrm{KJ} / \mathrm{m}^{3}$ \\
\hline [ = (2 x 1)] & $0,995^{(2)}$ & $(\%)$ \\
\hline 4) Carbono Não Oxidado: & $0,90^{(2)}$ & $(\%)$ \\
\hline 5) Poder Calorífico Inferior: & 0,80 & Diesel(L) / GNV(m $\left.{ }^{3}\right)$ \\
\hline 6) Equivalência GNV - Diesel & $0,{ }^{(1)} \mathrm{CTGÁS,} \mathrm{2000;}{ }^{(2)} \mathrm{IPCC}, 1996$.
\end{tabular}

Quanto aos índices de emissão dos GEEs, o IPCC (2006) os dimensiona para um consumo de $5 \mathrm{~km} / \mathrm{l}$ e de $9 \mathrm{~km} / \mathrm{l}$, respectivamente para veículos movidos a Diesel e a GNV. A Tabela 4 apresenta esses índices e também os valores ajustados para este estudo, conforme consumos adotados - $2 \mathrm{~km} / \mathrm{l}$ e $2,5 \mathrm{~km} / \mathrm{m}^{3}$ para ônibus a Diesel e GNV, respectivamente; e ainda, conforme o consumo de GNV em $\mathrm{km} / \mathrm{m}^{3}$ - equivalendo ao índice de $9 \mathrm{~km} / \mathrm{l}$, mas convertido em $11,25 \mathrm{~km} / \mathrm{m}^{3}$. 
Tabela 4 - Fatores de Emissão dos GEEs.

\begin{tabular}{|c|c|c|c|c|c|}
\hline GEE's & $\begin{array}{c}\text { Diesel }(\mathrm{kg} / \mathrm{TJ}) \\
5 \mathrm{~km} / \mathrm{l} \\
\end{array}$ & $\begin{array}{c}\text { GNV (Kg/TJ) } \\
11,25 \mathrm{~km} / \mathrm{m}^{3} \\
\end{array}$ & $\begin{array}{c}\text { Diesel }(\mathrm{kg} / \mathrm{TJ}) \\
2 \mathrm{~km} / \mathrm{l} \\
\end{array}$ & $\begin{array}{c}\text { GNV }(\mathrm{Kg} / \mathrm{TJ}) \\
2,5 \mathrm{~km} / \mathrm{m}^{3} \\
\end{array}$ & $\begin{array}{c}\text { Variação } \\
(\%)\end{array}$ \\
\hline $\mathrm{CO}_{2}$ & 74.100 & 56.100 & 29.640 & $12.466,67$ & $-57,94$ \\
\hline $\mathrm{CH}_{4}$ & 3,9 & 92 & 1,56 & 20,44 & $1.210,26$ \\
\hline $\mathrm{N}_{2} \mathrm{O}$ & 3,9 & 3 & 1,56 & 0,67 & $-57,05$ \\
\hline
\end{tabular}

Em se analisando isoladamente tais índices de emissão, observa-se que para os gases $\mathrm{CO}_{2} \mathrm{e}$ $\mathrm{N}_{2} \mathrm{O}$ existe um significativo potencial de redução das emissões do GNV confrontado com o Diesel. Já para o metano, ocorre um aumento percentual excessivo de emissões. Com o intuito de se condensar as emissões em forma mais objetiva de apresentação, existe a unidade $\mathrm{CO}_{2}$ eq (Dióxido de Carbono equivalente), sendo um parâmetro que reúne os índices do Potencial de Aquecimento Global (GWP - Global Potencial Warming) padronizados conforme o GWP do Dióxido de Carbono $\left(\mathrm{CO}_{2}\right)$. O GWP representa a estimativa do poder de ação dos GEEs, ocorrendo o mesmo com os outros fatores que afetam o balanço da radiação: os aerossóis, a variação da refletividade da superfície (albedo), a variabilidade solar, os vulcões e a variação do ozônio na estratosfera (CGEE, 2008, p.37).

Conforme o IPCC (2001), o GWP é calculado em diferentes períodos de tempo - 20, 100 e 500 anos, dos quais costuma-se adotar o período de 100 anos, para o qual os valores do índice são de 1, 21 e 310 para os gases $\mathrm{CO}_{2}, \mathrm{CH}_{4}$ e $\mathrm{N}_{2} \mathrm{O}$, respectivamente. Ao se multiplicar o índice GWP pelas quantidades emitidas em toneladas (t) dos gases $\mathrm{CO}_{2}$ (peso igual a 1), $\mathrm{CH}_{4}$ (peso igual a 23) e $\mathrm{N}_{2} \mathrm{O}$ (peso igual a 296), obtém-se o valor de $\mathrm{CO}_{2}$ eq das emissões totalizadas.

\section{RESULTADOS E DISCUSSÕES}

Correlacionando os índices de emissão dos GEEs (Tabela 4) com os valores das energias produzidas (Tabela 1), e a partir da aplicação da metodologia de cálculo para aferição das emissões em $\mathrm{CO}_{2}$ eq, a Tabela 5 expõe os valores das emissões da frota de ônibus em Natal, no período de 2006 a 2008 e média anual, para as matrizes Diesel e GNV. Sequencialmente, a Tabela 6 demonstra os valores das reduções (positivos) ou aumentos (negativos) de emissões (Diesel menos GNV) ocasionadas pela suposta substituição do Diesel pelo GNV.

Tabela 5 - Emissões dos GEEs e do $\mathrm{CO}_{2} \mathrm{eq}$ (t/ano) para o Diesel e GNV.

\begin{tabular}{cccccc}
\hline & $\mathbf{A N O}$ & $\mathbf{C O}_{2}$ & $\mathbf{C H}_{\mathbf{4}}$ & $\mathbf{N}_{\mathbf{2}} \mathbf{O}$ & $\mathbf{C O}_{\mathbf{2}} \mathbf{e q}$ \\
\hline \multirow{5}{*}{ Diesel } & $\mathbf{2 0 0 6}$ & $29.560,02$ & 1,56 & 1,56 & $29.563,07$ \\
\cline { 2 - 6 } & $\mathbf{2 0 0 7}$ & $28.935,04$ & 1,52 & 1,52 & $28.938,03$ \\
\cline { 2 - 6 } & $\mathbf{2 0 0 8}$ & $30.432,75$ & 1,60 & 1,60 & $30.435,89$ \\
\cline { 2 - 6 } & $\mathbf{2 0 0 6}$ a 2008 & $\mathbf{8 8 . 9 2 7 , 8 1}$ & $\mathbf{4 , 6 8}$ & $\mathbf{4 , 6 8}$ & $\mathbf{8 8 . 9 3 6 , 9 9}$ \\
\cline { 2 - 6 } & Média anual & $29.642,60$ & 1,56 & 1,56 & $29.645,66$ \\
\hline \hline \multirow{5}{*}{ GNV } & $\mathbf{2 0 0 6}$ & $14.426,61$ & 23,65 & 0,78 & $14.449,01$ \\
\cline { 2 - 6 } & $\mathbf{2 0 0 7}$ & $14.123,21$ & 23,16 & 0,76 & $14.145,15$ \\
\cline { 2 - 6 } & $\mathbf{2 0 0 8}$ & $14.853,12$ & 24,35 & 0,80 & $14.876,19$ \\
\cline { 2 - 6 } & $\mathbf{2 0 0 6}$ a 2008 & $\mathbf{4 3 . 4 0 2 , 9 3}$ & $\mathbf{7 1 , 1 6}$ & $\mathbf{2 , 3 3}$ & $\mathbf{4 3 . 4 7 0 , 3 5}$ \\
\cline { 2 - 6 } & Média anual & $14.467,64$ & 23,72 & 0,78 & $14.490,12$ \\
\hline
\end{tabular}


Preliminarmente à análise destes resultados, poder-se-ia salientar que, no cálculo da energia produzida pelos combustíveis, o fator de equivalência Diesel-GNV $\left(0,8 \mathrm{l} / \mathrm{m}^{3}\right)$ ocasiona uma maior demanda energética por parte do GNV, da ordem de 16,04\%, o que aparentemente tornaria a substituição desvantajosa sob a ótica ambiental. Contudo, ainda assim, se apreende que o total de emissões de GEEs para o GNV é consideravelmente menor, quando em comparação ao Diesel.

Tabela 6 - Valores Incrementais das emissões dos GEEs do Diesel em relação ao GNV.

\begin{tabular}{ccccc}
\hline ANO & $\mathbf{C O}_{2}$ & $\mathbf{C H}_{\mathbf{4}}$ & $\mathbf{N}_{\mathbf{2}} \mathbf{O}$ & $\mathbf{C O}_{\mathbf{2}} \mathbf{e q}$ \\
\hline $\mathbf{2 0 0 6}$ & $15.133,42$ & $-22,10$ & 0,78 & $15.114,06$ \\
\hline $\mathbf{2 0 0 7}$ & $14.811,83$ & $-21,63$ & 0,76 & $14.792,88$ \\
\hline $\mathbf{2 0 0 8}$ & $15.579,63$ & $-22,75$ & 0,80 & $15.559,70$ \\
\hline $\mathbf{2 0 0 6}$ a 2008 & $\mathbf{4 5 . 5 2 4 , 8 8}$ & $\mathbf{- 6 6 , 4 8}$ & $\mathbf{2 , 3 5}$ & $\mathbf{4 5 . 4 6 6 , 6 4}$ \\
\hline Média Anual & $15.174,96$ & $-22,16$ & 0,78 & $15.155,55$ \\
\hline
\end{tabular}

Ao analisar os dados apresentados observa-se que as emissões de $\mathrm{CH}_{4}$ sofreriam uma aumento equivalente a $1.420,4 \%$, e que as emissões de $\mathrm{CO}_{2}, \mathrm{~N}_{2} \mathrm{O}$ e $\mathrm{CO}_{2} \mathrm{eq}$ sofreriam uma redução de 51,2 \%, 49,8 \% e 48,9 \%, respectivamente, quando da substituição do Diesel pelo GNV.

Sumarizando, a Tabela 7 apresenta os valores percentuais das reduções de emissões potenciais (Tabela 4), efetivas e a diferença entre elas (os valores positivos correspondem a um aumento das emissões). A diferença percebida ao se cotejar as variações percentuais denotadas com as variações expostas na Tabela 4 deve-se, conforme relata Oliveira Júnior (2005), provavelmente, da maior quantidade de energia requerida pelos veículos movidos a GNV (16,04\%, conforme exposto acima) e que "somente com a melhoria tecnológica seria possível obter melhores percentuais de redução caso ocorresse a equivalência energética entre o Diesel e o GNV".

Tabela 7 - Valores percentuais das Variações Potenciais versus Efetivas dos GEEs.

\begin{tabular}{cccc}
\hline GEEs & $\begin{array}{c}\text { Variação } \\
\text { Potencial (\%) }\end{array}$ & $\begin{array}{c}\text { Variação } \\
\text { Efetiva (\%) }\end{array}$ & $\begin{array}{c}\text { Diferença } \\
(\%)\end{array}$ \\
\hline $\mathbf{C O}_{2}$ & $-57,94$ & $-51,19$ & $-6,75$ \\
\hline $\mathbf{C H}_{\mathbf{4}}$ & $1.210,26$ & $1.420,43$ & 210,17 \\
\hline $\mathbf{N}_{\mathbf{2}} \mathbf{O}$ & $-57,05$ & $-49,84$ & $-7,21$ \\
\hline $\mathbf{C O}_{\mathbf{2}} \mathbf{e q}$ & $-57,88$ & $-48,88$ & $-9,00$ \\
\hline
\end{tabular}

Face aos resultados observados e sob a ótica ambiental, estritamente- nota-se claramente que o uso do GNV como matriz energética na frota de ônibus urbanos em Natal acarretaria significativa redução das emissões de GEEs, sendo efetivamente de aproximadamente $49 \%$ (em termos de $\mathrm{CO}_{2} \mathrm{eq}$ ). Tal dado corrobora com estudos anteriores que mostram a redução de emissões pela mudança do combustível Diesel por GNV em ônibus.

Oliveira Júnior (2006), que usa a mesma base metodológica deste estudo, expõe uma redução de $12,61 \%$ quanto ao $\mathrm{CO}_{2}$ eq para a frota urbana do município de Fortaleza-CE, no período de 1991 a 2002. Julga-se que a diferença observada nos valores da redução estimada deva-se aos ajustes aqui feitos para a realidade local e consumo estimado, como explicitado na metodologia. Nogueira (2006) apresenta resultados de reduções de 40\% nas emissões de $\mathrm{CO}_{2}$ em medições de experimentos reais de substituição da matriz energética 
em ônibus na cidade de Porto Alegre-RS. Além do aspecto ambiental, o autor também afirma ter havido uma redução de $40 \%$ nos custos de operação do ônibus e terem sido conservados iguais os custos de manutenção. Watt (2001), em um relato geral acerca das experiências internacionais correlatas, denota que os "benefícios relacionados à redução de emissões de GEE's dos usos finais do gás natural são tipicamente avaliados em cerca de $10 \%$, proporcionada desde a produção até o consumo, em relação a combustíveis derivados de petróleo.

Assim, tais resultados permitem vislumbrar uma forma de mitigar os prejuízos ambientais causados pelas emissões de GEEs no transporte público por ônibus. Visionariamente, as decorrências citadas ainda permitem incentivar o desenvolvimento de um projeto MDL, que possa arrecadar recursos financeiros como a exemplo do projeto Transmilênio, implantado em Bogotá, Colômbia. O projeto, apenas pela reordenação, melhoramento e ampliação da frota de ônibus do transporte urbano municipal, contabilizou anualmente uma redução de mais de 300.000 toneladas de $\mathrm{CO}_{2}$, gerando o recebimento anual de recursos da ordem de R\$3.000.000,00 (NTU, 2009).

Tal exemplo, a despeito de um pouco segregado do escopo deste estudo, remete à discussão sobre a eficiência energética e ambiental do transporte urbano, em relacionando os transportes coletivos públicos e individuais particulares. Conforme o anuário 2009 da Associação Nacional das Empresas de Transportes Urbanos - NTU (NTU, 2009), os sistemas de ônibus brasileiros, que respondem por mais de $60 \%$ dos deslocamentos urbanos, contribuem com apenas $7 \%$ do total de emissões de $\mathrm{CO}_{2}$, enquanto que os automóveis leves, respondendo por menos de 30\% dos deslocamentos, são responsáveis por metade das emissões. $\mathrm{O}$ anuário analisa que a utilização do transporte público coletivo vem caindo ao longo dos anos e que, em contrapartida, o transporte individual (automóveis e motocicletas) vem assumindo maior participação na matriz modal, ocupando mais de $70 \%$ do espaço das vias. O anuário também coloca que o transporte individual apresenta "forte tendência de crescimento para os próximos anos, em função da política de incentivo às vendas de automóveis e motocicletas" e conclui que "do ponto de vista de eficiência energética e ambiental o transporte individual é o que apresenta pior desempenho, basta entender que um ônibus na rua equivale a 60 automóveis ou motos em termos de passageiros transportados” (NTU, 2009).

Além do exposto, é importante salientar a necessidade em se conduzir estudos que busquem o aumento da eficiência energética não só pelo uso de uma matriz eficaz, mas também pelo aprimoramento da tecnologia dos motores. Destaca-se que, como apresentado nas tabelas 2 e 3, o índice de emissão de carbono não oxidado é de $99 \%$ e $90 \%$ para o Diesel e GNV, respectivamente. Tais percentuais expõem uma alta ineficiência de aproveitamento (queima) dos combustíveis e denotam uma disparatada relação de custobenefício entre a energia produzida e gases emitidos, quando considerado o passivo socioambiental gerado.

Quanto a estas considerações, importa ver que a substituição da matriz energética Diesel pelo GNV caracteriza-se como uma, dentre outras, alternativa na redução das emissões de GEEs. Aliando-se a proposta de substituição da matriz energética a possíveis políticas de substituição da matriz modal do transporte, com o incremento do transporte coletivo e aprimoramento tecnológico quanto à eficácia energética, assomam-se os benefícios resultantes. 
Ainda, a fim de alvitrar posteriores estudos com análises mais abrangentes, podem ser contabilizados outros benefícios, como: a redução de externalidades econômico-sanitárias com redução de emissões de Gases de Efeito Locais e materiais particulados; redução da poluição sonora; maior aproveitamento do GNV como matriz energética, abundante em territórios estatal e nacional; e diminuição da dependência do Diesel como matriz energética.

\section{CONSIDERAÇÕES FINAIS}

De acordo com os estudos realizados, o potencial benefício ambiental advindo da substituição do Diesel pelo GNV no transporte público urbano é bastante expressivo, justificando a inclusão deste fator como mais um parâmetro a ser considerado numa análise global da alternativa de substituição.

Na hipótese de avanço dos estudos para implementação de tal substituição, é proeminente o aprofundamento dos estudos aqui apresentados, para validação em escala real e abrangendo os aspectos tecnológico, social, econômico, além do ambiental.

Por fim, frente a busca pela sustentabilidade e refinamento da eficácia tecnológicocientífíca em relação ao aprimoramento e/ou substituição de matrizes energéticas, acredita-se que esse estudo possa servir, cumulativa e cooperativamente, como somatório à idealização das necessárias soluções.

\section{REFERÊNCIAS BIBLIOGRÁFICAS}

1. CGEE - CENTRO DE GESTÃO E ESTUDOS ESTRATÉGICOS. Manual de Capacitação sobre Mudança do Clima e Projetos de Mecanismo de Desenvolvimento Limpo (MDL). Brasília, DF: 2008. 276 p.

2. CQNUMC - Convenção-Quadro das Nações Unidas sobre a Mudança do Clima. O protocolo de Kyoto. Disponível em <http:://www.mct.gov.br>. Acesso em: 12 Ago 2008, às 16:34h.

3. CTGÁS. Portaria Interministerial № 3, de 17 De Fevereiro de 2000. Diário Oficial da União (D.O.U.): 21/02/2000, Seção I-E.

4. PMF, Prefeitura Municipal De Fortaleza. Planilha para Cálculo de Custos e Tarifa: setembro/2002. Fortaleza: Empresa Técnica de Transporte Urbano S.A. ETTUSA, 2002.

5. IPCC, The Intergovernmental Panel on Climate Change. Revised 1996 IPCC Guidelines for National Greenhouse Gas Inventories: workbook. Vol.3, France: IPCC/OECD/IEA, 1996.

6. IPCC. 2006 IPCC Guidelines for National Greenhouse Gas Inventories. Japan: IGES, 2006.

7. IPCC, The Intergovernmental Pannel for Climate Change - Painel Intergovernamental para Mudança do Clima. Quarto relatório do painel intergovernamental sobre mudança do clima, AR4. Organização das Nações Unidas (ONU): 2007. 
8. FAJARDO, Elias. Entrevista - Washington Novaes: "O Brasil não coloca o meio ambiente no centro de sua estratégia nacional”. Senac e educação ambiental, Rio de Janeiro-RJ, v. 15, n. 1, p. 8-12, set./dez. 2006.

9. GUIMARÃES, Cláudia; FAJARDO, Elias. Aquecimento Global: o desafio do século. Senac e educação ambiental, Rio de Janeiro-RJ, v. 16, n. 1, p. 20-31, jan./abr. 2007.

10. HACKBART, Eugenio. Por que estes dados são escondidos? MetSul Meteorologia. Porto Alegre - RS: 06 Fev 2007. Disponível em: http://www.metsul.com/secoes/visualiza.php?cod_subsecao=33\&cod_texto=557> . Acesso em: 10 Dez 2009.

11. HACKBART, Eugenio. Terra vive resfriamento global. Correio do Povo. Porto Alegre - RS, 5 Jun 2008, p.31

12. MARTINS, Osvaldo Stella. Determinação do potencial de sequestro de carbono na recuperação de matas ciliares na região de São Carlos - SP. 136 f. Tese (Doutorado). São Carlos-SP: UFSCar, 2005.

13. NOGUEIRA, Sergei da Silva. Uso do GNV em ônibus urbano para operar em linha comercial - Projeto piloto Gasbus. 176 f. Dissertação (Mestrado em Engenharia Mecânica) - Faculdade de Engenharia da Universidade Federal do Rio Grande do Sul UFRGS, Porto Alegre, 2006.

14. NTU - ASSOCIAÇÃO NACIONAL DAS EMPRESAS DE TRANSPORTES URBANOS. Anuário 2008/2009. Brasília: 2009. 70 p.

15. OLIVEIRA FILHO, Alberto Dantas. Substituição de Diesel por Gás Natural em ônibus do Transporte Público Urbano. Dissertação (Mestrado em Energia) Universidade de São Paulo - USP, São Paulo, 2006.

16. OLIVEIRA JÚNIOR, João Alencar. A Utilização de Cenários Normativos para Formulação de Políticas Públicas: A Adoção do Gás Natural Veicular - GNV no Sistema de Transporte Público por Ônibus no Município de Fortaleza. 346f. Tese (Doutorado em Ciências em Engenharia de Transportes) - Universidade Federal do Rio de Janeiro - UFRJ, Rio de Janeiro, 2005.

17. RIBEIRO, S. K. et al. Barreiras na Implantação de Alternativas Energéticas para o Transporte Rodoviário no Brasil do Rio de Janeiro. Centro Clima, COPPE/ UFRJ, Rio de Janeiro. 2002.

18. RIBEIRO, S.K. Estudo das Vantagens Ambientais do Gás Natural Veicular: o caso do Rio de Janeiro. 1a ed., Rio de Janeiro: COPPE/UFRJ, 2001.

19. SCARPINELLA Gustavo D’Almeida. Reflorestamento no Brasil e o Protocolo de Quioto. 182 p. Dissertação (Mestrado). São Paulo-SP: USP, 2002.

20. WATT, G. M. Natural gas vehicle transit bus fleets: The current international experience. IANGV - International Association for Natural Gas Vehicles INC. Australia: Gas Technology Services, 2001. 